\title{
Safety of HTX-019 (intravenous aprepitant) and fosaprepitant in healthy subjects
}

Tom Ottoboni*,1, Michael Lauw², Mary Rose Keller², Matt Cravets ${ }^{3}$, Kimberly Manhard ${ }^{4}$ Neil Clendeninn ${ }^{\ddagger}, 5$ \& Barry Quart 6

${ }^{1}$ Pharmaceutical \& Translational Sciences, Heron Therapeutics, Inc., 4242 Campus Point Court, Suite 200, San Diego, CA 92121, USA

${ }^{2}$ Clinical Operations, Heron Therapeutics, Inc., 4242 Campus Point Court, Suite 200, San Diego, CA 92121, USA

${ }^{3}$ Biometrics, Heron Therapeutics, Inc., 4242 Campus Point Court, Suite 200, San Diego, CA 92121, USA

${ }^{4}$ Drug Development, Heron Therapeutics, Inc., 4242 Campus Point Court, Suite 200, San Diego, CA 92121, USA

${ }^{5}$ Clinical, Heron Therapeutics, Inc., 4242 Campus Point Court, Suite 200, San Diego, CA 92121, USA

${ }^{6}$ Heron Therapeutics, Inc., 4242 Campus Point Court, Suite 200, San Diego, CA 92121, USA

*Author for correspondence: Tel.: +1650 261 3003; Fax: +1650 365 6490; tottoboni@herontx.com

$\ddagger$ Employee at time of study, currently consultant to Heron Therapeutics, Inc.

Aim: Evaluate safety of HTX-019, a novel polysorbate 80 - and synthetic surfactant-free intravenous formulation of neurokinin 1 receptor antagonist aprepitant for chemotherapy-induced nausea and vomiting. Methods: Two open-label, randomized, two-way crossover studies evaluated treatment-emergent adverse events (TEAEs) in 200 healthy subjects. Subjects received HTX-019 $130 \mathrm{mg}$ (30-min infusion) and fosaprepitant $150 \mathrm{mg}$ (20- or 30-min infusion), with $\geq 7$-day washout between doses. Results: Less than or equal to 30 min after start of infusion, TEAEs occurred in 5 (3\%) HTX-019 and 30 (15\%) fosaprepitant recipients. No HTX-019 recipients had infusion-site adverse events, versus 15 (8\%) fosaprepitant recipients. Treatment-related dyspnea occurred in one HTX-019 and six fosaprepitant recipients. No severe/serious TEAEs occurred; all TEAEs resolved. Conclusion: HTX-019 may provide a safer aprepitant formulation than fosaprepitant for chemotherapy-induced nausea and vomiting prevention.

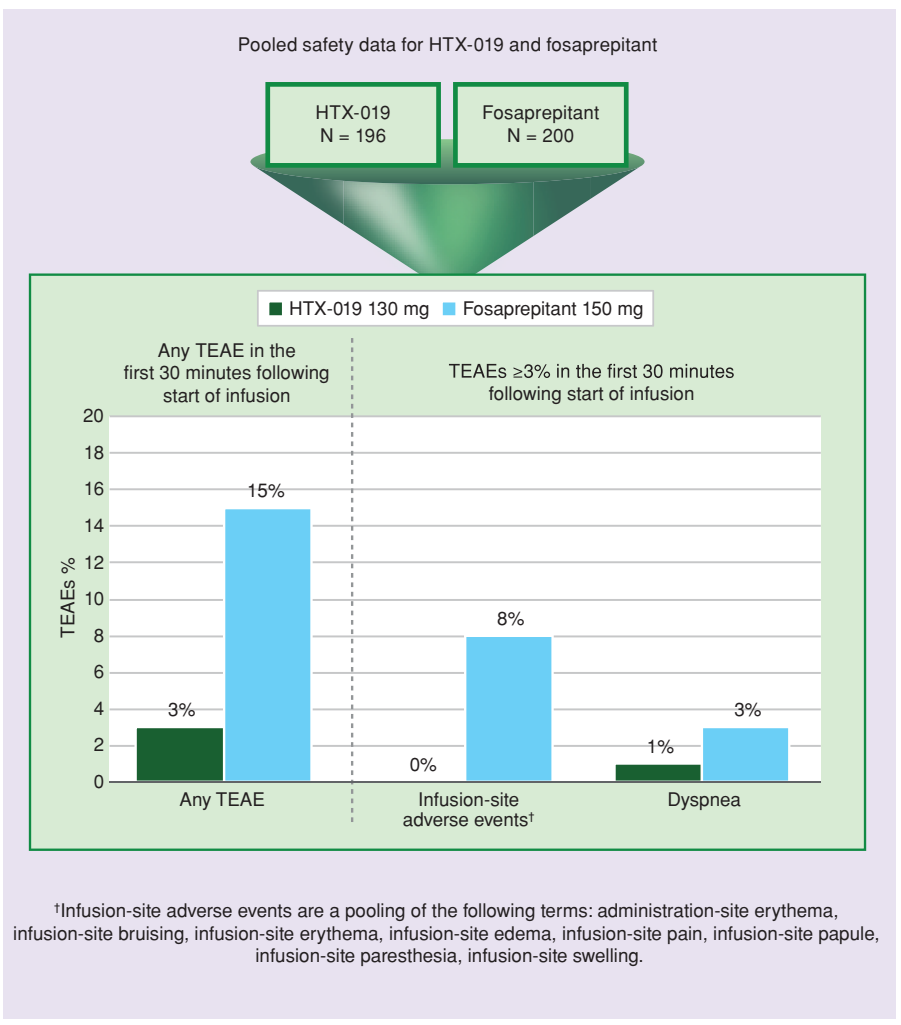

Future 8 Medicine 
First draft submitted: 18 April 2018; Accepted for publication: 17 May 2018; Published online: 6 June 2018

Keywords: antiemetics $\bullet$ aprepitant $\bullet$ safety

Chemotherapy-induced nausea and vomiting (CINV) continues to have a negative effect on the quality of life of patients with cancer, despite the availability of effective antiemetic regimens [1-3]. Approximately $60-80 \%$ of oncology patients report suffering from nausea or vomiting as a result of chemotherapy, despite using prophylactic antiemetics [4,5]. Poorly controlled CINV may cause patients to discontinue chemotherapy, potentially adversely affecting survival outcomes $[4,6]$, and may increase healthcare costs associated with cancer treatment and supportive care $[4,7]$.

Antiemetic guidelines from the American Society of Clinical Oncology, the Multinational Association for Supportive Care in Cancer/European Society for Medical Oncology and the National Comprehensive Cancer Network (NCCN) provide recommendations for antiemetic regimens based on the emetogenicity of chemotherapy, categorized as moderately (MEC) and highly emetogenic chemotherapy (HEC) [8-11]. For patients receiving HEC and some MEC regimens, the NCCN and Multinational Association for Supportive Care in Cancer/European Society for Medical Oncology guidelines generally recommend a three-drug antiemetic regimen of a 5-hydroxytryptamine type $3\left(5-\mathrm{HT}_{3}\right)$ receptor antagonist (RA), dexamethasone, and a neurokinin 1 (NK-1) RA [8,9,11]. The American Society of Clinical Oncology guidelines recommend adding olanzapine to this three-drug regimen for HEC regimens; this is also proffered as an option by the NCCN guidelines [10,11]. However, despite these comprehensive antiemetic guidelines, CINV control remains a challenge [4].

Aprepitant, an NK-1 RA, was approved by the US FDA in 2003 for CINV prevention in patients receiving MEC or HEC regimens [12-14]; however, aprepitant has low water solubility, so it was available only in the oral formulation [13]. Several years later, in 2008, a prodrug of aprepitant, fosaprepitant, was developed and approved for intravenous administration for CINV prevention [14]. Fosaprepitant is more water soluble than aprepitant, but still required a powerful surfactant, polysorbate 80 , to be formulated for intravenous administration [14]. Polysorbate 80 is used to solubilize fosaprepitant and other poorly soluble drugs, and has been associated with both hypersensitivity systemic reactions (HSRs) and infusion-site adverse events (ISAEs). The published literature shows a wide range in the incidence of fosaprepitant-related ISAEs, mainly due to differences in reporting [15-22]. The US prescribing information for fosaprepitant (Emend ${ }^{\circledR}$ iv. [intravenous]) includes a warning and precaution regarding HSRs such as anaphylaxis and anaphylactic shock, which may occur either during or after infusion of the drug, as well as for infusion-site reactions (ISRs), including thrombophlebitis, necrosis and vasculitis [14]. The ISRs observed with fosaprepitant are exacerbated by the use of anthracycline-based chemotherapy [14,17-21] and by administration via a peripheral line [23]. These findings have led some institutions, such as the Mayo Clinic, to change their preferred NK-1 RA from fosaprepitant, which had been incorporated into its treatment guidelines in 2011, back to aprepitant $[17,18]$.

An iv. formulation of an NK-1 RA without polysorbate 80 or other similarly toxic synthetic surfactants could reduce the risk of HSRs and ISRs. HTX-019 (CINVANTI ${ }^{\circledR}$ ), a novel formulation of aprepitant free of polysorbate 80 and other synthetic surfactants, was recently approved by the FDA in combination with other antiemetics for the prevention of acute and delayed CINV associated with MEC or HEC [24]. The initial bioequivalence study (Study 104) showed that single-dose HTX-019 $130 \mathrm{mg}$ iv. was bioequivalent to single-dose fosaprepitant $150 \mathrm{mg}$ iv., both infused over $30 \mathrm{~min}$ [25]. Because the fosaprepitant prescribing information recommends infusion over 20-30 min [14], a second Phase I, open-label, randomized, two-sequence, two-treatment, two-period crossover study (Study 106) was conducted to evaluate pharmacokinetics, bioequivalence and safety of a 30-min infusion of HTX-019 compared with a 20-min infusion of fosaprepitant. As observed in the earlier study, HTX-019 and fosaprepitant were also bioequivalent in Study 106 (area under the curve [AUC] from time 0 to time of last measurable plasma concentration $\left[\mathrm{AUC}_{0-\mathrm{t}}\right]$, AUC from time 0 extrapolated to infinity $\left[\mathrm{AUC}_{0-\mathrm{inf}}\right]$ and plasma concentration at $12 \mathrm{~h}$ $\left.\left[\mathrm{C}_{12 \mathrm{~h}}\right]\right)$. Plasma concentrations of aprepitant over time in the two studies were comparable [25]. Reported here are the pooled safety data in 200 healthy subjects from both studies (Study 106 and Study 104). 


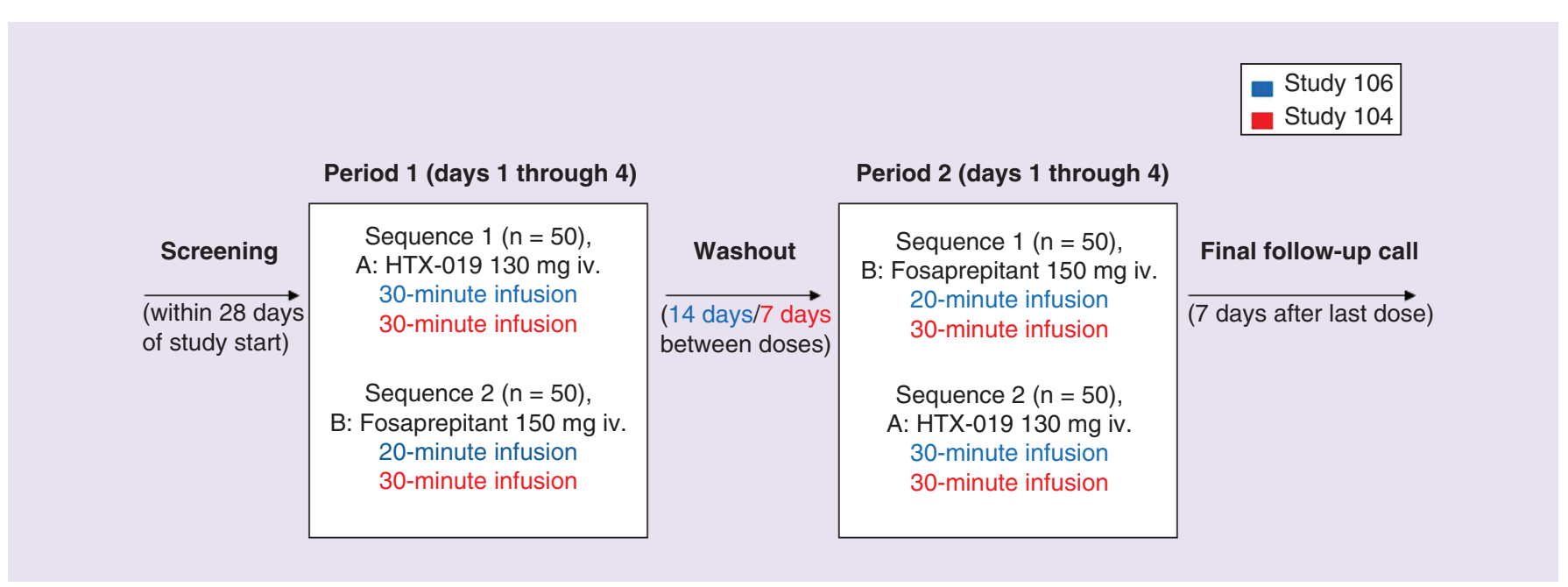

Figure 1. Study design for Studies 106 and 104. Confinement in the clinic from the morning of day -1 through day 4 of each treatment period (through the pharmacokinetic collection at $72 \mathrm{~h}$ on day 4), for a total of approximately 5 days per treatment period. iv.: Intravenous.

Adapted with permission from [25] @ Dove Press Ltd (2018); permission conveyed through Copyright Clearance Center, Inc.

\section{Methods}

\section{Study design \& objectives}

Both studies were Phase I, single-center, randomized, open-label studies. The first, Study 104, was a two-sequence crossover study in which healthy volunteers received single-dose HTX-019 $130 \mathrm{mg}$ iv. or fosaprepitant $150 \mathrm{mg}$ iv., each infused over $30 \mathrm{~min}$, and was recently published [25]. Study 106 was conducted as a two-part study that included a pilot study (Part A) used to inform sampling times and a two-sequence crossover study (Part B) in which healthy volunteers received single-dose HTX-019 $130 \mathrm{mg}$ iv. as a 30-min infusion and fosaprepitant $150 \mathrm{mg}$ iv. as a 20-min infusion (Figure 1) [14,25]. Here we report safety data for Part B of Study 106 as well as pooled safety data for Studies 106 and 104. Studies 106 and 104 assessed the safety and tolerability of HTX-019 and fosaprepitant at their respective dosages and iv. infusion times [25].

For Study 106, enrolled subjects were to be aged $18-55$ years, with bodyweight $\geq 50 \mathrm{~kg}$ and BMI $18-35 \mathrm{~kg} / \mathrm{m}^{2}$, inclusive, and in good health based on medical history, physical examination and clinical laboratory results at screening. Subjects were to be excluded if they had a history or presence of a clinically significant abnormal 12-lead ECG; an ECG with QT interval corrected using Fridericia's formula $>470 \mathrm{~ms}$ for women or $>450 \mathrm{~ms}$ for men; a PR interval $>240 \mathrm{~ms}$, QRS complex $>110 \mathrm{~ms}$ or history of QT interval prolongation; or a sustained supine systolic blood pressure $(\mathrm{BP})>150 \mathrm{~mm} \mathrm{Hg}$ or $<100 \mathrm{~mm} \mathrm{Hg}$ or diastolic BP $>95 \mathrm{~mm} \mathrm{Hg}$ at screening. Subjects who were pregnant or breastfeeding were also excluded. Inclusion and exclusion criteria for Study 104 were identical to those for Study 106, the only difference being the use of Bazett's formula for ECG with QT interval correction for Study $104[25]$.

\section{Treatment regimens \& administration}

For Studies 106 and 104, subjects were randomly assigned to one of two treatment sequences: HTX-019 then fosaprepitant (AB) or fosaprepitant then HTX-019 (BA). Treatment A was HTX-019 $130 \mathrm{mg}$ as a 30-min iv. infusion, and treatment B was fosaprepitant $150 \mathrm{mg}$ as a 30-min iv. infusion (Study 104) or a 20-min iv. infusion (Study 106). There was a minimum 14-day washout period between each dose for Study 106 (Figure 1) and a minimum 7-day washout period for Study 104 [25].

HTX-019 $130 \mathrm{mg}$ was prepared as follows: $23 \mathrm{ml}$ of 0.9\% sodium chloride was added to a 150 - $\mathrm{ml}$ bag containing approximately $109 \mathrm{ml}$ prefilled $0.9 \%$ sodium chloride, then $18 \mathrm{ml}$ of HTX-019 was added, for a total volume of $150 \mathrm{ml}$ (final aprepitant concentration of $0.87 \mathrm{mg} / \mathrm{ml}$ ) and administered as an infusion [24].

Fosaprepitant $150 \mathrm{mg}$ for injection was prepared according to the prescribing information as follows: $36 \mathrm{ml}$ of $0.9 \%$ sodium chloride was added to a $150-\mathrm{ml}$ admix bag containing approximately $109 \mathrm{ml}$ prefilled $0.9 \%$ sodium chloride, then $5 \mathrm{ml}$ of $0.9 \%$ sodium chloride was added to a vial of fosaprepitant for injection (sourced via 
Table 1. Subject demographics and baseline characteristics (Studies 106 and 104, safety populations).

\begin{tabular}{|c|c|c|c|c|c|c|}
\hline \multirow[t]{3}{*}{ Parameters } & \multicolumn{3}{|c|}{ Study 106} & \multicolumn{3}{|c|}{ Study 104} \\
\hline & Sequence $1 \mathrm{AB}^{\dagger}$ & Sequence $\mathbf{2} \mathbf{B A}^{\dagger}$ & Overall & Sequence $1 \mathrm{AB}^{\dagger}$ & Sequence $2 \mathbf{B A}^{\dagger}$ & Overall \\
\hline & $n=50$ & $n=50$ & $n=100$ & $n=50$ & $n=50$ & $n=100$ \\
\hline Age, mean (SD), years & $32(10)$ & $35(10)$ & $33(10)$ & $38(10)$ & $33(9)$ & $35(10)$ \\
\hline Weight, mean (SD), kg & $81(14)$ & $78(14)$ & $80(14)$ & $77(13)$ & $79(15)$ & $78(14)$ \\
\hline Height, mean (SD), cm & $174(7)$ & $167(10)$ & $171(9)$ & $170(9)$ & $172(10)$ & $171(10)$ \\
\hline BMI, mean (SD), $\mathrm{kg} / \mathrm{m}^{2}$ & $27(4)$ & $28(4)$ & $27(4)$ & $27(3)$ & $27(4)$ & $27(4)$ \\
\hline \multicolumn{7}{|l|}{ Sex, n (\%): } \\
\hline - Female & $1(2)$ & $32(64)$ & $33(33)$ & $18(36)$ & $18(36)$ & $36(36)$ \\
\hline - Male & $49(98)$ & $18(36)$ & $67(67)$ & $32(64)$ & $32(64)$ & $64(64)$ \\
\hline Race, white, n (\%) & $18(36)$ & $18(36)$ & $36(36)$ & $30(60)$ & $25(50)$ & $55(55)$ \\
\hline $\begin{array}{l}\text { Ethnicity, } \mathrm{n}(\%) \\
\text { Not Hispanic or Latino }\end{array}$ & $43(86)$ & $43(86)$ & $86(86)$ & $47(94)$ & $41(82)$ & $88(88)$ \\
\hline \multicolumn{7}{|c|}{$\begin{array}{l}\text { The denominator was based on the number of subjects in the safety population in each cohort and overall with data for the given characteristic. } \\
{ }^{\dagger} \text { Treatment A: HTX-019 } 130 \mathrm{mg}, 30 \text {-min iv. infusion; treatment B: Fosaprepitant } 150 \mathrm{mg}, 20 \text {-min iv. infusion. } \\
\text { Fosaprepitant: Fosaprepitant (fosaprepitant dimeglumine) for injection, for intravenous use; HTX-019: HTX-019 (aprepitant) injectable emulsion, for intravenous use; iv.: Intravenous; } \\
\text { SD: Standard deviation. } \\
\text { Data taken from [25]. }\end{array}$} \\
\hline
\end{tabular}

commercial channels); the entire volume was transferred from the vial to the iv. bag, for a total volume of $150 \mathrm{ml}$ (final fosaprepitant concentration of $1.0 \mathrm{mg} / \mathrm{ml}$ ) and administered as an infusion [14].

For both studies, subjects were confined to the clinic from the morning of day 1 through $72 \mathrm{~h}$ (day 4) after dosing for each treatment period [25].

\section{Safety assessments}

Safety assessments for Studies 106 and 104 included treatment-emergent adverse events (TEAEs) overall, by severity (mild, moderate or severe) and by relation to study treatment (definitely, probably, possibly or not related), as determined by the investigator. Physical examination, 12-lead ECG and clinical laboratory assessments were performed. Vital signs (oral body temperature, supine BP and heart rate) were also taken.

\section{Statistical analysis}

In each of Studies 106 and 104, a sample size of 50 subjects per treatment sequence (100 subjects for each study, 200 subjects in total) was determined to be adequate to evaluate the safety of HTX-019 [25]. The safety population comprised all enrolled subjects who received at least one dose of study drug. Safety analyses for both studies included occurrences of TEAEs overall and by severity (mild, moderate or severe), related adverse events (AEs), serious AEs (SAEs), related SAEs, and changes in 12-lead ECGs, clinical laboratory testing and vital signs [25]. Related TEAEs included all those events classified by the investigator as possibly, probably or definitively related to study drug. Unrelated TEAEs were those events classified as not related to study drug. Events for which the investigator did not record relationship to study drug were considered related to study drug. TEAEs occurring within the first 30 and 60 min after infusion start were also summarized. An analysis of the TEAE rate per subject-day was performed using a negative binomial regression model. The model compared treatment groups adjusted for sequence and included the natural $\log$ transformation of total time on study as an offset term. The adjusted event rates per subject-day and associated 95\% CIs, the event rate ratios and associated 95\% CIs, and p-values were calculated.

\section{Results}

Patients

The demographics and baseline characteristics of subjects enrolled in Studies $106(\mathrm{n}=100$; safety population) and $104(\mathrm{n}=100$; safety population) are shown in Table 1 [25]. A total of 95 subjects completed Study 106; two subjects discontinued because of AEs, two subjects withdrew and one subject had a protocol deviation.

Demographics and baseline characteristics were comparable between studies. In Study 106, more men than women were enrolled in treatment sequence HTX-019 then fosaprepitant ( 49 vs 1), while fewer men than women were enrolled in treatment sequence fosaprepitant then HTX-019 (18 vs 32). However, the proportion of males and females was similar in the two studies, with 33\% females in Study 106 and 36\% females in Study 104 (Table 1) [25]. 
Table 2. Summary of treatment-emergent adverse events (Studies 106 and 104, safety populations).

\begin{tabular}{|c|c|c|c|c|c|c|}
\hline \multirow[t]{4}{*}{ Category } & \multicolumn{2}{|c|}{ Study 106} & \multicolumn{2}{|c|}{ Study 104} & \multicolumn{2}{|c|}{ Pooled } \\
\hline & $\begin{array}{l}\text { HTX-019 } \\
130 \mathrm{mg}^{\dagger}\end{array}$ & $\begin{array}{l}\text { Fosaprepitant } \\
150 \mathrm{mg}^{\ddagger}\end{array}$ & $\begin{array}{l}\text { HTX-019 } \\
130 \mathrm{mg}^{\dagger}\end{array}$ & $\begin{array}{l}\text { Fosaprepitant } \\
150 \mathrm{mg}^{\dagger}\end{array}$ & HTX-019 $130 \mathrm{mg}$ & $\begin{array}{l}\text { Fosaprepitant } \\
150 \mathrm{mg}\end{array}$ \\
\hline & $\mathrm{n}=97$ & $n=100$ & $\mathrm{n}=99$ & $n=100$ & $N=196$ & $N=200$ \\
\hline & n (\%) & n (\%) & $n(\%)$ & n (\%) & n (\%) & $n(\%)$ \\
\hline Subjects with at least 1 TEAE, n (\%) & $13(13)$ & $30(30)$ & $21(21)$ & $28(28)$ & $34(17)$ & $58(29)$ \\
\hline Subjects with a related TEAE, $n(\%)$ & $10(10)$ & $27(27)$ & $15(15)$ & $28(28)$ & $25(13)$ & $55(28)$ \\
\hline $\begin{array}{l}\text { Subjects with a TEAE leading to study drug } \\
\text { discontinuation, n (\%) }\end{array}$ & $1(1)$ & $2(2)$ & 0 & $2(2)$ & $1(1)$ & $4(2)$ \\
\hline $\begin{array}{l}\text { Subjects with a TEAE leading to study withdrawal, } \\
\text { n (\%) }\end{array}$ & $1(1)$ & $1(1)$ & 0 & $2(2)$ & $1(1)$ & $3(2)$ \\
\hline $\begin{array}{l}\text { Subjects with a related TEAE leading to study } \\
\text { withdrawal, } n(\%)\end{array}$ & $1(1)$ & $1(1)$ & 0 & $2(2)$ & $1(1)$ & $3(2)$ \\
\hline Number of TEAEs, $n$ & 18 & 54 & 27 & 54 & 45 & 108 \\
\hline Number of related TEAEs, $n$ & 15 & 46 & 18 & 52 & 33 & 98 \\
\hline $\begin{array}{l}\text { Number of TEAEs leading to study drug } \\
\text { discontinuation, } n\end{array}$ & 2 & 3 & 0 & 6 & 2 & 9 \\
\hline Number of TEAEs leading to study withdrawal, $n$ & 2 & 1 & 0 & 2 & 2 & 3 \\
\hline $\begin{array}{l}\text { Number of related TEAEs leading to study } \\
\text { withdrawal, } n\end{array}$ & 2 & 1 & 0 & 2 & 2 & 3 \\
\hline \multicolumn{7}{|c|}{$\begin{array}{l}\text { Because of the crossover nature of the study, if the same adverse event was reported in the first and/or second treatment period by the same subject, then the overall column } \\
\text { counted the adverse event only once for that subject. The denominator for percentages was based on the number of subjects in the safety population exposed to each treatment } \\
\text { and overall. Related events included events classified as possibly, probably and definitely related. Events were classified according to MedDRA, Version } 18.1 \text {. } \\
\text { †Administered intravenously for } 30 \text { min. } \\
\text { ‡Administered intravenously for } 20 \text { min. } \\
\text { Fosaprepitant: Fosaprepitant (fosaprepitant dimeglumine) for injection, for intravenous use; HTX-019: HTX-019 (aprepitant) injectable emulsion, for intravenous use; iv.: Intravenous; } \\
\text { MedDRA: Medical Dictionary for Regulatory Activities; TEAE: Treatment-emergent adverse event. } \\
\text { Data taken from [25]. }\end{array}$} \\
\hline
\end{tabular}

\section{Safety}

A summary of TEAEs for Studies 106 and 104 over the entire study period is shown in Table 2. In Study 106, the proportion of subjects experiencing at least one TEAE was higher with fosaprepitant than with HTX-019 (30 vs 13\%, respectively) and the number of TEAEs was higher with fosaprepitant than with HTX-019 (54 vs 18, respectively). The proportion of subjects experiencing TEAEs deemed to be related to study drug was also higher with fosaprepitant than with HTX-019 (27 vs 10\%), and the number of related TEAEs was higher with fosaprepitant than with HTX-019 (46 vs 15, respectively). Findings were similar for Study 104 (Table 2) [25].

\section{Common TEAEs}

Pooled safety data from Studies 106 and 104 showed that TEAEs were reported in 17\% of HTX-019 recipients $(\mathrm{N}=196)$ and $29 \%$ of fosaprepitant recipients $(\mathrm{N}=200)$ (Table 3). The most commonly reported TEAEs after HTX-019 administration were headache (3\%) and fatigue (2\%). The most commonly reported TEAEs after fosaprepitant administration were ISAEs (10\%) and headache (7\%). Except for lethargy in Study 106 and fatigue in Study 104 [25], all TEAEs occurred at a lower incidence when subjects received HTX-019 than when they received fosaprepitant.

In Study 106, three subjects (3\%) had TEAEs of dyspnea that were all considered related to fosaprepitant; one subject (1\%) had the infusion discontinued. In Study 106, one subject (1\%) had a TEAE of dyspnea that was considered possibly related to HTX-019, which led to discontinuation of the infusion. In Study 104, three subjects (3\%) reported dyspnea during fosaprepitant infusion, all of which were considered related to the study drug. Two subjects (2\%) had the fosaprepitant infusion discontinued. One subject (1\%) receiving HTX-019 had a TEAE of dyspnea 5 days after the infusion, likely due to an upper respiratory infection, which was not considered related to HTX-019 [25].

\section{TEAEs within first 30 min}

For the pooled safety data, the percentage of subjects who reported a TEAE was higher with fosaprepitant (15\%) than with HTX-019 (3\%) within the first $30 \mathrm{~min}$ after the start of each infusion (Table 4). The majority of TEAEs 
Table 3. Most common treatment-emergent adverse events: incidence $\geq 2 \%$ with any treatment (Studies 106 and 104).

\begin{tabular}{|c|c|c|c|c|c|c|}
\hline \multirow[t]{2}{*}{ Preferred term } & \multicolumn{2}{|c|}{ Study 106} & \multicolumn{2}{|c|}{ Study 104} & \multicolumn{2}{|c|}{ Pooled } \\
\hline & HTX-019 $130 \mathrm{mg}^{\dagger}$ & $\begin{array}{l}\text { Fosaprepitant } \\
150 \mathrm{mg}^{\ddagger}\end{array}$ & HTX-019 $130 \mathrm{mg}^{\dagger}$ & $\begin{array}{l}\text { Fosaprepitant } \\
150 \mathrm{mg}^{\dagger}\end{array}$ & HTX-019 $130 \mathrm{mg}$ & Fosaprepitant $150 \mathrm{mg}$ \\
\hline & $n=97$ & $\mathrm{n}=100$ & $n=99$ & $n=100$ & $N=196$ & $N=200$ \\
\hline Any TEAE & $13(13)$ & $30(30)$ & $21(21)$ & $28(28)$ & $34(17)$ & $58(29)$ \\
\hline $\begin{array}{l}\text { Infusion-site adverse } \\
\text { events } \$\end{array}$ & 1 (1) & $11(11)$ & $2(2)$ & $9(9)$ & $3(2)$ & $20(10)$ \\
\hline Dyspnea & $1(1)$ & $3(3)$ & $1(1)$ & $3(3)$ & $2(1)$ & $6(3)$ \\
\hline Nausea & $1(1)$ & $1(1)$ & $1(1)$ & $5(5)$ & $2(1)$ & $6(3)$ \\
\hline Abdominal pain & $1(1)$ & $3(3)$ & 0 & $2(2)$ & $1(1)$ & $5(3)$ \\
\hline Dizziness & 0 & 0 & $1(1)$ & $4(4)$ & $1(1)$ & $4(2)$ \\
\hline Diarrhea & $1(1)$ & $2(2)$ & 0 & $1(1)$ & $1(1)$ & $3(2)$ \\
\hline Lethargy & $2(2)$ & 0 & 0 & 0 & $2(1)$ & 0 \\
\hline \multicolumn{7}{|c|}{ 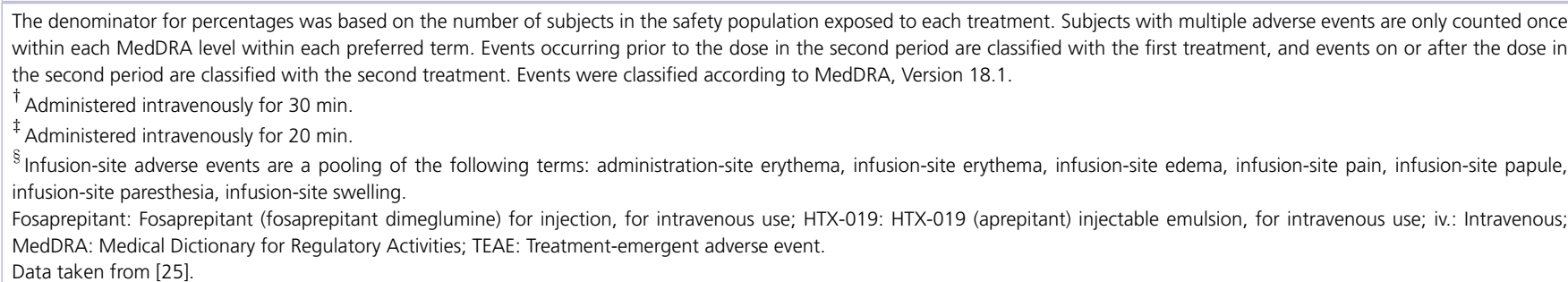 } \\
\hline
\end{tabular}

Table 4. Treatment-emergent adverse events (incidence $\geq 2 \%$ with any treatment) in the first 30 min following start of infusion (Studies 106 and 104).

\begin{tabular}{|c|c|c|c|c|c|c|}
\hline \multirow[t]{4}{*}{ Preferred term } & \multicolumn{2}{|c|}{ Study 106} & \multicolumn{2}{|c|}{ Study 104} & \multicolumn{2}{|c|}{ Pooled } \\
\hline & HTX-019 $130 \mathrm{mg}^{\dagger}$ & $\begin{array}{l}\text { Fosaprepitant } \\
150 \mathrm{mg}^{\ddagger}\end{array}$ & HTX-019 $130 \mathrm{mg}^{\dagger}$ & $\begin{array}{l}\text { Fosaprepitant } \\
150 \mathrm{mg}^{\dagger}\end{array}$ & HTX-019 $130 \mathrm{mg}$ & Fosaprepitant $150 \mathrm{mg}$ \\
\hline & $\mathrm{n}=97$ & $n=100$ & $\mathrm{n}=99$ & $n=100$ & $N=196$ & $N=200$ \\
\hline & n (\%) & n (\%) & n (\%) & n (\%) & $n(\%)$ & n (\%) \\
\hline Any $\mathrm{TEAE}^{\S}$ & $5(5)$ & $13(13)$ & 0 & $17(17)$ & $5(3)$ & $30(15)$ \\
\hline $\begin{array}{l}\text { Infusion-site adverse } \\
\text { events } \mathbb{I}\end{array}$ & 0 & $8(8)$ & 0 & $7(7)$ & 0 & $15(8)$ \\
\hline Dyspnea & $1(1)$ & $3(3)$ & 0 & $3(3)$ & $1(1)$ & $6(3)$ \\
\hline Nausea & $1(1)$ & $1(1)$ & 0 & $3(3)$ & $1(1)$ & $4(2)$ \\
\hline Dizziness & 0 & 0 & 0 & $3(3)$ & 0 & $3(2)$ \\
\hline Headache & 0 & 0 & 0 & $2(2)$ & 0 & $2(1)$ \\
\hline Pain in extremity & 0 & 0 & 0 & $2(2)$ & 0 & $2(1)$ \\
\hline Lethargy & $2(2)$ & 0 & 0 & 0 & $2(1)$ & 0 \\
\hline \multicolumn{7}{|c|}{$\begin{array}{l}\text { The denominator for percentages is based on the number of subjects in the safety population exposed to each treatment. Subjects with multiple adverse events are only counted once } \\
\text { within each MedDRA level within each preferred term. Events were classified according to MedDRA, Version 18.1. } \\
{ }^{\dagger} \text { Administered intravenously for } 30 \text { min. } \\
{ }^{\ddagger} \text { Administered intravenously for } 20 \text { min. } \\
{ }_{\text {Beginning within } 30 \text { min after the start of infusion. }} \text { I Infusion-site adverse events are a pooling of the following terms: administration-site erythema, infusion-site bruising, infusion-site erythema, infusion-site edema, infusion-site pain, } \\
\text { infusion-site papule, infusion-site paresthesia, infusion-site swelling. } \\
\text { Fosaprepitant: Fosaprepitant (fosaprepitant dimeglumine) for injection, for intravenous use; HTX-019: HTX-019 (aprepitant) injectable emulsion, for intravenous use; iv.: Intravenous; } \\
\text { MedDRA: Medical Dictionary for Regulatory Activities; TEAE: Treatment-emergent adverse event. } \\
\text { Data taken from [25]. }\end{array}$} \\
\hline
\end{tabular}


occurred within the first 30 min after start of infusion of study drug for both Studies 106 and 104 [25]. For Study 106, the percentage of subjects who reported a TEAE and the number of TEAEs were higher with fosaprepitant (13\%, 13 events) than with HTX-019 (5\%, five events) within the first 30 min after the start of each infusion (Table 4). The most commonly reported TEAEs in Study 106 were ISAEs (8\%) with fosaprepitant and lethargy (2\%) with HTX-019. For Study 104, no TEAEs were observed in subjects receiving HTX-019 and the most commonly reported TEAEs with fosaprepitant were ISAEs (7\%).

\section{TEAEs between 30 \& 60 min}

Few TEAEs occurred between 30 and 60 min after start of infusion. For Study 106, two TEAEs were reported by one subject (one event of fatigue and presyncope) who received fosaprepitant. For Study 104, four TEAEs were reported by four subjects (one event each: headache, infusion-site pain, muscle tightness and somnolence) receiving fosaprepitant; one TEAE was reported by one subject (infusion-site pain) receiving HTX-019; however these TEAEs were resolved by the end of the study [25].

There were no severe TEAEs, deaths or SAEs in either study, and all TEAEs had resolved by the end of each study. There were no clinically meaningful changes in clinical laboratory, physical examination, vital sign or ECG findings in either study.

In Study 106, a negative binomial analysis of TEAE rates found that the estimated event rate per subject-day for HTX-019 was 0.01 TEAEs per subject-day compared with 0.04 TEAEs per subject-day for fosaprepitant, and the event rate ratio was $0.30(\mathrm{p}=0.0011)$. A similar analysis for Study 104 found that the estimated event rate was 0.03 TEAEs per subject-day for HTX-019 compared with 0.06 TEAEs per subject-day for fosaprepitant, and the event rate ratio was $0.5(\mathrm{p}=0.0274)[25]$.

\section{Discussion}

Bioequivalence of HTX-019 to fosaprepitant was established by the two open-label studies (Studies 106 and 104). HTX-019 was generally well tolerated in both studies, and overall HTX-019 safety profiles were similar. Because both studies were conducted in healthy volunteers, relatedness to treatment of the TEAEs observed could be clearly assessed without interference from concomitant chemotherapy. Evaluation of the TEAEs during the infusion period suggests the likelihood that the events were related to drug administration. The combined data from both studies showed that a single dose of HTX-019 was associated with a lower incidence of dyspnea, compared with fosaprepitant. Overall, the proportion of subjects who reported any TEAEs and the number of TEAEs were lower with HTX-019 than with fosaprepitant, as were the proportion of subjects with treatment-related TEAEs and the number of treatment-related TEAEs, and no new safety signals were observed for HTX-019. There were no serious or severe TEAEs or deaths in either study, and all TEAEs had resolved by the end of each study.

In particular, TEAEs detected within the first 30 and $60 \mathrm{~min}$ after infusion start were evaluated to determine the safety profiles of HTX-019 and fosaprepitant when the maximum plasma concentrations of aprepitant occur. Pooled safety data from Studies 106 and 104 showed that considerably fewer subjects receiving HTX-019 (3\%), compared with those receiving fosaprepitant (15\%), reported TEAEs within $30 \mathrm{~min}$ of infusion start, and these findings were similar for both studies individually. Moreover, the majority of the TEAEs occurred within the first 30 min after the start of infusion for each drug, with few TEAEs occurring between 30 and 60 min after the start of infusion. A statistically significant negative binomial analysis showed that the estimated event rate per subject-day for HTX-019 was approximately one-third to one-half the rate observed for fosaprepitant for Studies 106 and 104 , respectively.

Further, the types of treatment-related TEAEs occurring within the first 30 min of infusion were different for subjects treated with HTX-019 versus those treated with fosaprepitant. This finding could be due to the prodrug or to differences in the formulations of these drugs. ISAEs are reported to be the major limiting adverse reaction during fosaprepitant administration [26].

A retrospective review of 127 charts identified ISAEs and systemic reactions associated with iv. fosaprepitant in patients receiving anthracycline plus cyclophosphamide-based chemotherapy regimens. Results showed that 137 individual ISAEs were observed in 32 patients [23]. This result was reflected in our pooled findings for Studies 106 and 104, where ISAEs were the most commonly reported treatment-related TEAE during fosaprepitant administration, occurring in $10 \%$ of subjects, compared with only $2 \%$ of subjects during HTX-019 administration. In both Studies 106 and 104, treatment-related dyspnea was reported for six subjects overall during fosaprepitant infusion, compared with one subject during HTX-019 infusion. In Study 104, there was one additional report of 
dyspnea, not treatment related, by a subject receiving HTX-019; the dyspnea occurred 5 days after infusion and was likely due to an upper respiratory infection. One subject receiving HTX-019 discontinued treatment from Study 106 because of dyspnea, whereas a total of three subjects receiving fosaprepitant in Studies 106 and 104 discontinued treatment because of dyspnea.

A possible limitation of both studies is that they were unblinded; however, this open-label design is typical of bioequivalence studies. The crossover design and the large number of subjects enrolled and treated in both studies mitigate intersubject and study-drug administration variations. Both studies were designed to identify all TEAEs attributable to study drugs by utilizing healthy volunteers not receiving chemotherapy. Thus, studying healthy volunteers was appropriate, given the limited interaction between aprepitant and chemotherapy seen across multiple studies involving different tumor types, different chemotherapy regimens and multiple chemotherapy cycles [12].

HTX-019, an NK-1 RA, provides a polysorbate 80-free and synthetic surfactant-free intravenous formulation of aprepitant. NK-1 RAs are commonly prescribed as part of three- or four-drug regimens recommended for CINV prevention by accepted antiemetic treatment guidelines [8-11]. With the inclusion of HTX-019 in the NCCN guidelines as an option for the NK-1 RA given along with a 5- $\mathrm{HT}_{3} \mathrm{RA}$, dexamethasone and/or olanzapine, it provides an antiemetic regimen for prevention of acute and delayed CINV associated with MEC or HEC [11,24]. Aprepitant and its prodrug fosaprepitant are approved in combination with other antiemetics for CINV prophylaxis in HEC and MEC patients, and their efficacy and safety have been established over a decade or more [9,12,27]. However, the fosaprepitant formulation contains polysorbate 80 , a synthetic surfactant that is associated with a number of adverse reactions, including HSRs [28,29]. The prescribing information for commercially available fosaprepitant includes a warning and precaution regarding HSRs, such as anaphylaxis and anaphylactic shock, and ISRs such as thrombophlebitis, necrosis and vasculitis [14]. Furthermore, it has been reported that ISRs are exacerbated when fosaprepitant is administered during anthracycline-based chemotherapy [14,17-21] and via a peripheral line [23].

In 2017, an iv. formulation of the NK-1 RA rolapitant containing a synthetic surfactant, polyoxyl 15 hydroxystearate (Kolliphor ${ }^{\circledR}$ HS 15), was approved in the USA, in combination with other antiemetics, for the prevention of CINV [30,31]. Recently, on 16 January, 2018, an FDA MedWatch safety alert was issued to healthcare providers, warning against HSRs including anaphylaxis and anaphylactic shock, which may occur during or following administration of iv. rolapitant. The alert recommended avoiding administration of this drug if the patient was hypersensitive to any of the ingredients of the drug formulation [32]. Given the warning regarding HSRs, the manufacturer issued a press release on 28 February, 2018, announcing the suspension of iv. rolapitant distribution [33]. The synthetic surfactant in iv. rolapitant, polyoxyl 15 hydroxystearate, has been previously associated with HSRs in dogs and may be the cause of the AEs observed with iv. rolapitant [34].

\section{Conclusion}

Our findings show that a single dose of HTX-019 $130 \mathrm{mg}$ administered as a 30-min iv. infusion was well tolerated, with fewer AEs than seen with fosaprepitant. Therefore, HTX-019, an iv. formulation of aprepitant that is free of polysorbate 80 and other synthetic surfactants, may provide a safer alternative approach to delivering aprepitant than fosaprepitant for the prevention of CINV.

Financial \& competing interests disclosure

T Ottoboni, M Lauw, MR Keller, M Cravets, K Manhard, N Clendeninn and B Quart report employment by Heron Therapeutics, Inc. T Ottoboni, K Manhard, N Clendeninn and B Quart report leadership roles with Heron Therapeutics, Inc. T Ottoboni, M Lauw, MR Keller, M Cravets, N Clendeninn and B Quart report stock ownership in Heron Therapeutics, Inc. This study was funded by Heron Therapeutics, Inc., San Diego, CA, USA. The authors have no other relevant affiliations or financial involvement with any organization or entity with a financial interest in or financial conflict with the subject matter or materials discussed in the manuscript apart from those disclosed.

Writing assistance was utilized in the production of this manuscript. Medical writing support was provided by N Parikh and YE Yarker, of SciStrategy Communications, and funded by Heron Therapeutics, Inc. 
Ethical conduct of research

Studies 106 and 104 were conducted in accordance with the International Conference on Harmonisation Guideline for Good Clinical Practice and the Declaration of Helsinki. Each study was approved by the institutional review board for the clinical site. Written informed consent was obtained from each subject.

\section{Open access}

This work is licensed under the Attribution-NonCommercial-NoDerivatives 4.0 Unported License. To view a copy of this license, visit http://creativecommons.org/licenses/by-nc-nd/4.0/

\section{Summary points}

- Consensus guidelines recommend either a three- or four-drug antiemetic regimen for chemotherapy-induced nausea and vomiting control.

- Intravenous (iv.) fosaprepitant formulated with polysorbate 80 has been associated with hypersensitivity reactions, including anaphylaxis and anaphylactic shock; infusion-site reactions, such as thrombophlebitis, necrosis and vasculitis; and infusion-site adverse events.

- iv. rolapitant, formulated with polyoxyl 15 hydroxystearate, has had the US FDA MedWatch safety alert issued, warning against hypersensitivity reactions including anaphylaxis and anaphylactic shock; the manufacturer has announced suspension of distribution of this drug.

- HTX-019, a novel formulation of aprepitant free of polysorbate 80 and other synthetic surfactants, was recently approved by the FDA.

- Pooled safety data from two open-label, randomized, two-way crossover studies show that HTX-019 was well tolerated.

- The proportion of subjects reporting any treatment-related adverse event and the number of treatment-related adverse events were lower with HTX-019 than with fosaprepitant.

- HTX-019 may provide a safer alternative formulation of aprepitant than fosaprepitant for chemotherapy-induced nausea and vomiting prevention.

\section{References}

Papers of special note have been highlighted as: • of interest; $\bullet \bullet$ of considerable interest

1. Ballatori E, Roila F, Ruggeri B et al. The impact of chemotherapy-induced nausea and vomiting on health-related quality of life. Support. Care Cancer 15(2), 179-185 (2007).

2. Grassi L, Berardi MA, Ruffilli F et al. Role of psychosocial variables on chemotherapy-induced nausea and vomiting and health-related quality of life among cancer patients: a European study. Psychother. Psychosom. 84(6), 339-347 (2015).

3. Hilarius DL, Kloeg PH, Van Der Wall E, Van Den Heuvel JJ, Gundy CM, Aaronson NK. Chemotherapy-induced nausea and vomiting in daily clinical practice: a community hospital-based study. Support. Care Cancer 20(1), 107-117 (2012).

4. Sommariva S, Pongiglione B, Tarricone R. Impact of chemotherapy-induced nausea and vomiting on health-related quality of life and resource utilization: a systematic review. Crit. Rev. Oncol. Hematol. 99, 13-36 (2016).

- Comprehensive review outlining evidence of the effect of chemotherapy-induced nausea and vomiting on patient quality of life and its healthcare cost burden.

5. Oncology Nursing Society. Chemotherapy-induced nausea and vomiting. www.ons.org/practice-resources/pep/chemotherapy-induced-nausea-and-vomiting

6. Hassan BA, Yusoff ZB. Negative impact of chemotherapy on breast cancer patients QOL - utility of antiemetic treatment guidelines and the role of race. Asian Pac. J. Cancer Prev. 11(6), 1523-1527 (2010).

7. Burke TA, Wisniewski T, Ernst FR. Resource utilization and costs associated with chemotherapy-induced nausea and vomiting (CINV) following highly or moderately emetogenic chemotherapy administered in the US outpatient hospital setting. Support. Care Cancer 19(1), 131-140 (2011).

8. Herrstedt J, Roila F, Warr D et al. 2016 updated MASCC/ESMO consensus recommendations: prevention of nausea and vomiting following high emetic risk chemotherapy. Support. Care Cancer 25(1), 277-288 (2017).

9. Roila F, Warr D, Hesketh PJ et al. 2016 updated MASCC/ESMO consensus recommendations: prevention of nausea and vomiting following moderately emetogenic chemotherapy. Support. Care Cancer 25(1), 289-294 (2017).

10. Hesketh PJ, Kris MG, Basch E et al. Antiemetics: American Society of Clinical Oncology Clinical Practice Guideline update. J. Clin. Oncol. 35(28), 3240-3261 (2017).

11. NCCN. NCCN Clinical Practice Guidelines in Oncology: Antiemesis - Version 2 (2018). www.nccn.org/professionals/physician_gls/f_guidelines.asp 
12. Aapro M, Carides A, Rapoport BL, Schmoll HJ, Zhang L, Warr D. Aprepitant and fosaprepitant: a 10-year review of efficacy and safety. Oncologist 20(4), 450-458 (2015).

- Review focusing on key studies of aprepitant and fosaprepitant, which examines their safety and efficacy data and their use in chemotherapy-induced nausea and vomiting prevention.

13. Emend (aprepitant) capsules, for oral use, prescribing information. Merck \& Co., NJ, USA (2017).

14. Emend (fosaprepitant dimeglumine) for injection, for intravenous use, prescribing information. Merck \& Co., NJ, USA (2018).

15. Saito $\mathrm{H}$, Yoshizawa $\mathrm{H}$, Yoshimori $\mathrm{K}$ et al. Efficacy and safety of single-dose fosaprepitant in the prevention of chemotherapy-induced nausea and vomiting in patients receiving high-dose cisplatin: a multicentre, randomised, double-blind, placebo-controlled Phase III trial. Ann. Oncol. 24(4), 1067-1073 (2013).

16. Grunberg S, Chua D, Maru A et al. Single-dose fosaprepitant for the prevention of chemotherapy-induced nausea and vomiting associated with cisplatin therapy: randomized, double-blind study protocol - EASE. J. Clin. Oncol. 29(11), 1495-1501 (2011).

17. Hegerova LT, Leal AD, Grendahl DC et al. An analysis of fosaprepitant-induced venous toxicity in patients receiving highly emetogenic chemotherapy. Support. Care Cancer 23(1), 55-59 (2015).

18. Leal AD, Kadakia KC, Looker S et al. Fosaprepitant-induced phlebitis: a focus on patients receiving doxorubicin/cyclophosphamide therapy. Support. Care Cancer 22(5), 1313-1317 (2014).

- Retrospective chart review of patients receiving doxorubicin/cyclophosphamide chemotherapy, which investigates incidence of fosaprepitant-induced infusion-site adverse events.

19. Tsuda T, Kyomori C, Mizukami T et al. Infusion site adverse events in breast cancer patients receiving highly emetic chemotherapy with prophylactic anti-emetic treatment with aprepitant and fosaprepitant: a retrospective comparison. Mol. Clin. Oncol. 4(4), 603-606 (2016).

20. Fujii T, Nishimura N, Urayama KY et al. Differential impact of fosaprepitant on infusion site adverse events between cisplatin- and anthracycline-based chemotherapy regimens. Anticancer Res. 35(1), 379-383 (2015).

21. Sato Y, Kondo M, Inagaki A et al. Highly frequent and enhanced injection site reaction induced by peripheral venous injection of fosaprepitant in anthracycline-treated patients. J. Cancer 5(5), 390-397 (2014).

- Study in patients treated with anthracycline, identifying incidence of infusion-site reactions associated with fosaprepitant administered via peripheral venous injection.

22. Azmin MN, Stuart JF, Calman KC, Florence AT. Effects of polysorbate 80 on the absorption and distribution of oral methotrexate (MTX) in mice. Cancer Chemother. Pharmacol. 9(3), 161-164 (1982).

23. Boccia R, Geller R, Clendennin N, Ottoboni T. A retrospective chart review of hypersensitivity and infusion-site adverse events (ISAEs) associated with fosaprepitant IV in patients receiving anthracycline and cyclophosphamide (AC)-based chemotherapy. Support. Care Cancer 25(Suppl. 2), Abstract eP003 (2017).

- Study identifying risk of infusion-site adverse events and systemic reactions associated with fosaprepitant in patients receiving anthracycline and cyclophosphamide chemotherapy.

24. Cinvanti (aprepitant) injectable emulsion, for intravenous use, prescribing information. Heron Therapeutics, Inc., CA, USA (2017).

25. Ottoboni T, Keller MR, Cravets M, Clendeninn N, Quart B. Bioequivalence of HTX-019 (aprepitant IV) and fosaprepitant in healthy subjects: a Phase I, open-label, randomized, 2-way crossover evaluation. Drug Des. Devel. Ther. 12, 429-435 (2018).

-• Phase I trial of HTX-019 proving bioequivalence of HTX-019 to fosaprepitant.

26. Candelario N, Lu ML. Fosaprepitant dimeglumine for the management of chemotherapy-induced nausea and vomiting: patient selection and perspectives. Cancer Manag. Res. 8, 77-82 (2016).

27. Kraut L, Fauser AA. Anti-emetics for cancer chemotherapy-induced emesis: potential of alternative delivery systems. Drugs 61(11), 1553-1562 (2001).

28. Coors EA, Seybold H, Merk HF, Mahler V. Polysorbate 80 in medical products and nonimmunologic anaphylactoid reactions. Ann. Allergy Asthma Immunol. 95(6), 593-599 (2005).

29. Ten Tije AJ, Verweij J, Loos WJ, Sparreboom A. Pharmacological effects of formulation vehicles: implications for cancer chemotherapy. Clin. Pharmacokinet. 42(7), 665-685 (2003).

30. Varubi (rolapitant) injectable emulsion, for intravenous use, prescribing information. Tesaro, Inc., MA, USA (2018).

31. Wang X, Zhang ZY, Powers D et al. Bioequivalence of intravenous and oral rolapitant: results from a randomized, open-label pivotal study. J. Clin. Pharmacol. 57(12), 1600-1606 (2017).

32. US FDA. Varubi (rolapitant) injectable emulsion: health care provider letter - anaphylaxis and other serious hypersensitivity reactions. 16 January 2018. www.fda.gov/Safety/MedWatch/SafetyInformation/SafetyAlertsforHumanMedicalProducts/ucm592592.htm

33. Tesaro announces fourth-quarter and full-year 2017 operating results. http://ir.tesarobio.com/news-releases/news-release-details/tesaro-announces-fourth-quarter-and-full-year-2017-operating 
34. The European Agency for the Evaluation of Medicinal Products. Polyethylene glycol stearates and polyethylene glycol 15 hydroxystearate - summary report.

www.ema.europa.eu/docs/en_GB/document_library/Maximum_Residue_Limits_-_Report/2009/11/WC500015762.pdf 
